\title{
Trends in economic research: An international perspective ${ }^{1}$
}

\author{
Ana Rute Cardoso* \\ Institute for Economic Analysis (CSIC) and IZA Bonn \\ Paulo Guimarães \\ Moore School of Business, University of South Carolina \\ Klaus F. Zimmermann \\ IZA Bonn, Bonn University, and DIW Berlin
}

\begin{abstract}
Given the recent efforts in several countries to reorganize the research institutional setting to improve research productivity, our analysis addresses the following questions: To which extent has the recent awareness over international quality standards in economics around the world been reflected in research performance? How have individual countries fared? Do research quantity and quality indicators tell us the same story? We concentrate on trends taking place since the beginning of the 1990s and rely on a very comprehensive database of scientific journals, to provide a cross-country comparison of the evolution of research in economics. Our findings indicate that Europe is catching-up with the US but, in terms of influential research, the US maintains a dominant position. The main continental European countries, Germany, France, Italy and Spain, experienced some of the largest growth rates in economic scientific output. Other European countries, namely the UK, Norway, the Netherlands, Denmark, and Sweden, have shown remarkable progress in per capita output. Collaborative research seems to be a key factor explaining the relative success of some European countries, in particular when it comes to publishing in top journals, attained predominantly through international collaborations.
\end{abstract}

Keywords: research performance; publications; rankings; Europe; North-America; US JEL codes: A10, I20

Forthcoming in Kyklos

\footnotetext{
${ }^{1}$ We thank the research assistance of Yuanyuan Zeng, Victorya Pinter, Daniela Goed, and Dan Yang. The first author acknowledges the support of the Spanish Ministry of Science and Innovation (grant ECO2009-07958), the Barcelona GSE Research Network and the Government of Catalonia.

IAE-CSIC, Campus UAB, 08193 Bellaterra, Barcelona, Spain. E-mail: anarute.cardoso@ iae.csic.es .
} 


\section{Introduction}

Just a couple of decades ago, the standards to evaluate research performance in economics varied widely across countries, with entrenched national traditions defining the methodological approaches favored, the type of issues covered, as well as the language used. The prevailing notion was that country specificities prevented the use of common standards. Frey and Eichenberger (1993) provide a concise summary of the differences between the American and European research markets and their incentive systems, reporting nevertheless early signs of convergence, as Europe moved towards the North-American benchmark. Nowadays, the idea of relying on world-recognized quality standards to allocate research funding on a competitive basis or to take decisions on recruitment and promotion of academic staff is widespread. Worldwide, there is increasing pressure to publish as a condition to get an academic job or a promotion and this globalization of the standards of academic work has been reflected in a rising number of existing journals and a change in their role and publishing procedures (see Frey et al, 2009).

Studies focusing on the sources of the low European research performance in economics when compared to the USA invariably emphasize the relevance of incentives, both at individual and department levels, and the need to promote profound institutional reforms in most European countries (see for example Drèze and Estevan, 2007). Aghion et al (2010) emphasize the causal impact of autonomy in decision-making combined with market competition (for grants, students and staff) on university output (publications and patents) and the role of assessment exercises to guarantee accountability.

Accordingly, different countries have been undertaking efforts to reorganize their research institutional setting. In particular, the European Union places great emphasis on promoting mobility of staff, cross-country cooperation and research excellence more broadly. There seems to be an expectation that Europe will move towards American standards of research productivity, based on the on-going economic and cultural integration that renders the market wider and more transparent and the fact that a new generation of economists is growing equipped with the analytic tools and the motivation to place European research at a higher level (Kirman and Dahl, 1994; Borghans and Coervers, 2009; Colander, 2008). A few studies for other academic fields report trends that question the traditional American hegemony (Shelton and Holdridge, 2004; Glaenzel et al, 2008).

Given this setting, we address the following questions: To which extent has the recent awareness over international quality standards in economics around the world been reflected 
in research performance? How have individual countries fared? Do research quantity and quality indicators tell us the same story?

We concentrate on trends taking place since the beginning of the 1990s and rely on a very comprehensive database, covering all 170 journals that show up simultaneously in Econlit and the Social Science Citation Index (SSCI) for at least five years during the 1991 to 2006 period. Finally, our focus is on cross-country comparisons, an area where, despite widespread curiosity and strong a priori beliefs, little comprehensive analysis has been undertaken, due to data limitations.

Section 2 describes the data collection and data handling procedures. Section 3 overviews the trend in research production by broad continents. Sections 4 and 5 scrutinize whether the extension of coverage of journals by international databases, as opposed to considering a stable set of journals, may inflate the growth of some continents, and whether quality indicators still report the same trends. Section 6 provides a comparative perspective on several countries, identifying contrasts among their paths.

\section{Data and concepts used}

Our selection of journals was obtained by combining information from the Econlit database with that from the Social Science Citation Index (SSCI) database. Econlit, the American Economic Association's electronic bibliography, is a comprehensive database that indexes economics related literature from a large number of scientific journals. Importantly, beyond the commonly used bibliographic items, the Econlit includes information on JEL codes and the affiliation of each of the authors. On the other hand, the SSCI includes information on a large number of journals in many different fields but offers a classification into scientific areas, one of those being Economics. The SSCI has the additional advantage of collecting information on citations. Both databases have been expanding their coverage at a rapid pace and currently include core journals in economics as well as others only loosely related to economics.

Therefore, to define a comprehensive set of economics journals that may be considered representative of the field according to internationally widely accepted standards, we opted to include in our database all journals that showed up in both the Econlit and the SSCI (Economics) for at least five consecutive years between 1991 and 2006. This resulted in a set of 170 journals, which includes this journal, Kyklos (an appendix with the full list of journals and their coverage is available from the authors upon request). Our database contains information for a total of 100,404 articles including bibliographic information, author affiliation and JEL code (from Econlit) and the number of citations collected by each article 
from publication until 2008 (from SSCI). In our analysis we refer to this as the list of all journals.

For reasons to be clarified in the analysis, we may at times be interested in the set of journals that are present in our database throughout the 16-year period. We refer to this set as the established journals, which includes Kyklos and another 109 journals (the full list is available from the authors), which represent a total of 79,161 articles.

Finally, we will also work with a restricted set of top journals (6,811 articles). To define the list of top economics journals, we considered five alternative rankings available in the literature, which are widely known: Kalaitzidakis et al (2003); Kodrzycki (2006) ranking based on journal impact ("within economic impact)"; Axarloglou and Theoharakis (2003); Barrett et al (2000) (Table 3, column 2); and Laband and Piette (1994) (Table A2). If a journal was ranked among the top-10 in all five rankings, we defined it as a top journal. In other words, there had to be consensus electing a journal as a top journal for it to be included in our selection. This criterion resulted in the following list of top journals: American Economic Review, Econometrica, Journal of Economic Theory, Journal of Political Economy, Quarterly Journal of Economics, and Review of Economic Studies. According to Fonseca (2010), three of these journals are US journals, two are international journals (Econometrica and Journal of Economic Theory) and one is Europe-based (Review of Economic Studies).

Crossing the information from the two databases allowed us to correct several mistakes and to exclude articles that could not be legitimately classified as scientific articles. ${ }^{2}$ Also, throughout this period, several journals changed name. In this case, we used the latest designation to identify the unique journal. Moreover, for articles with more than three authors, Econlit would until recently only report the first author and affiliation, using "et al" to refer to the remaining authors. To obviate this problem, we completed the information on authors and affiliations by inspecting each individual article.

We identified the country of origin of each author of an article by using the first affiliation reported. In the analysis articles were assigned to countries in proportion to the origin of their authors $^{3}$ and the overall production of each country was computed by tallying up all these shares. This proportionality procedure was used to allocate both the number of articles and their citations. Countries were grouped into the following continental groups: North-America, Other America, Europe, Asia, Oceania, and Africa. ${ }^{4}$

\footnotetext{
${ }^{2}$ We excluded errata, comments, obituaries, book reviews, editorials, rejoinders, messages, letters, prefaces, forewords, disclaimers, etc.

${ }^{3}$ To illustrate, the present article would contribute $1 / 3$ to Spain, $1 / 3$ to the US and $1 / 3$ to Germany.

${ }^{4}$ The coding is self-explanatory for almost all countries; Israel, Turkey and Russia were coded as Europe.
} 
When reporting the number of articles per capita, we considered the countries' population in 2006 posted on the US Bureau of the Census International Database (US Bureau Census, 2009).

\section{General trends in research in economics: Europe is catching up and Asia is rising}

Figure 1 reports the contribution of each continent to world academic production in economics, considering all journals included in our database. Europe has been steadily increasing its contribution, while in recent years Asia is showing signs of a promising takeoff. That has been achieved at the expense of a decline in the relative position of NorthAmerica. Indeed, in 1991 Europe had a share of $24 \%$ of the articles, while North-America had $66 \%$. By 2006, the European share had risen to $40 \%$ and the North-American one had declined to $45 \%$. Asia, on the other hand, increased its contribution from $3 \%$ to $9 \%$. Throughout the period, Oceania's contribution remained close to $4 \%$, while Other America and Africa had a minor contribution, close to $1 \%$ by 2006 .

Figure 1 - Evolution of the share of articles by continent, all journals

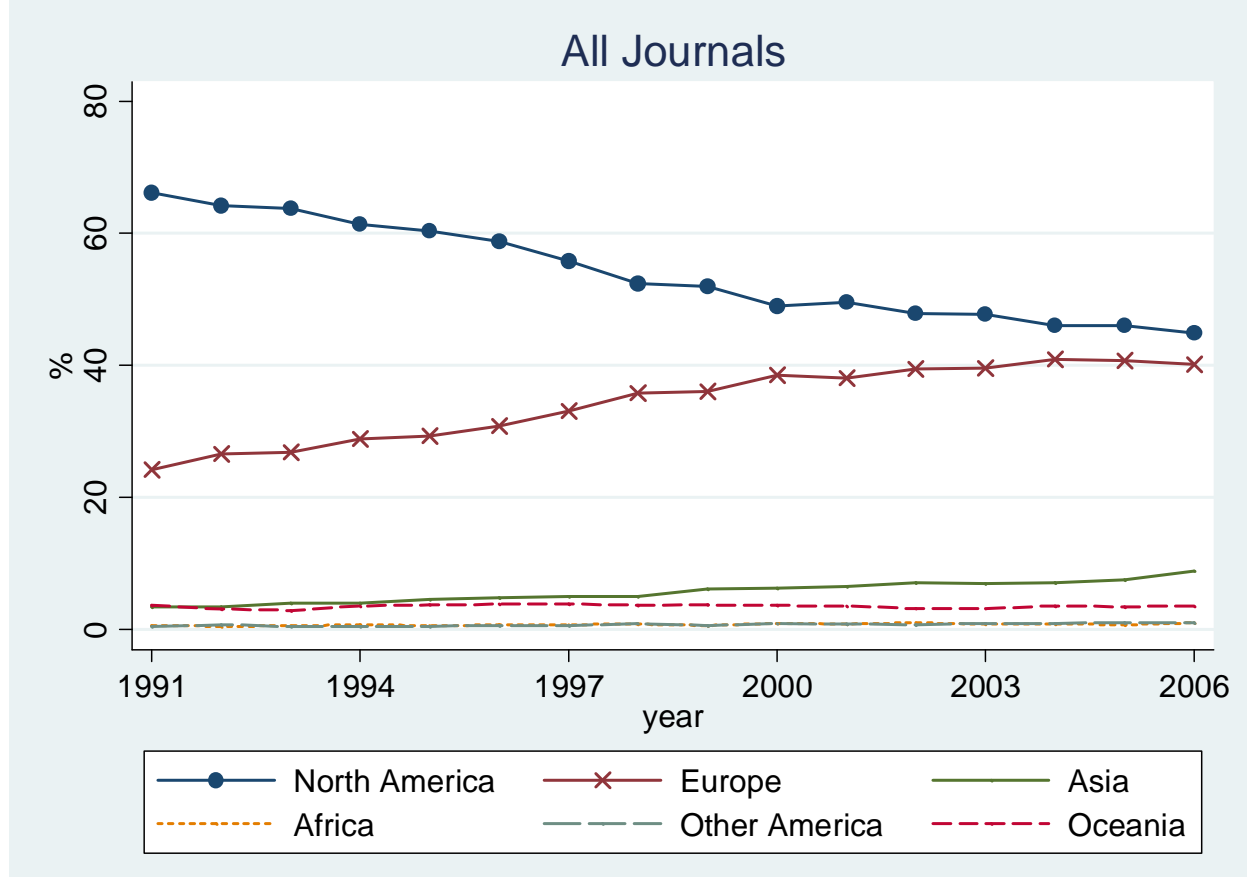

Source: Authors computations based on Econlit and SSCI.

The major trend, a convergence of European and North-American research outputs, seems rather impressive. However, closer scrutiny should address two relevant questions. First of all, does that trend reflect an actual increase in European production or does it simply mirror a change in the way we count outputs? When comparing research performance across groups of 
researchers, it is standard practice to focus on all journals covered by a database ${ }^{5}$ and to disregard the fact that the coverage of the database has broadened. However, it is often argued that Europe has been strengthening its competitiveness, by succeeding in including more of its journals in databases routinely used to measure academic production in economics, such as Econlit and SSCI. Therefore, the apparent increase in production could result from the extension of the data sources to outlets where Europeans are traditionally strong, bearing little relation to changes in actual research productivity as it would have been captured had the criterion remained unchanged. A second issue that must be addressed is: To which extent are these trends in quantity related to trends in quality of scientific production? The two following sections address these issues.

\section{Journal coverage: entrant journals in international bibliographic data sources reflect Europe's search for a stronger role in world research}

The set of journals added over time to the database includes journals where Europeans have a relatively strong position (see table 1). In fact, in 2006 European authors had a share of 38\% of the articles in journals present in the database throughout the 16 year period (established journals), whereas in the journals that entered after 1991 their share rises to $45 \%$ and yet again to $55 \%$ when considering journals that entered the database after 1999. In that sense, Europe has been successful at increasing its competitiveness under the current evaluation system in economics.

Table 1 - Share of articles in 2006, by geographic origin (percentage)

\begin{tabular}{l|c|c|c}
\hline & Established & \multicolumn{2}{|c}{ Entrant journals in: } \\
\cline { 3 - 4 } & journals & $1992-2006$ & $2000-2006$ \\
\hline North America & 48.25 & 36.61 & 33.02 \\
Europe & 38.07 & 45.38 & 55.02 \\
Asia & 7.70 & 11.81 & 3.75 \\
Africa & 1.02 & 1.08 & 0.32 \\
Other America & 1.09 & 1.02 & 1.42 \\
Oceania & 3.52 & 3.58 & 4.98 \\
\hline
\end{tabular}

Note: Established journal - journal listed in our database throughout the period 1991 to 2006; entrant journal journal that entered the database after 1991.

Source: Authors computations based on Econlit and SSCI.

This leads us to perform the same exercise of computing the share of articles published by researchers from different geographical origins, but restricting now the sample to those journals that were in the database throughout the period (see figure 2). As such, we are measuring trends in research production keeping unchanged the criterion to define what is considered a research output.

\footnotetext{
${ }^{5}$ See for example Coupé (2003) and Combes and Linnemer (2003), or Shelton and Holdridge (2004) and Glaenzel et al (2008), who analysed the technology field.
} 
Figure 2 - Evolution of the share of articles by continent, established journals

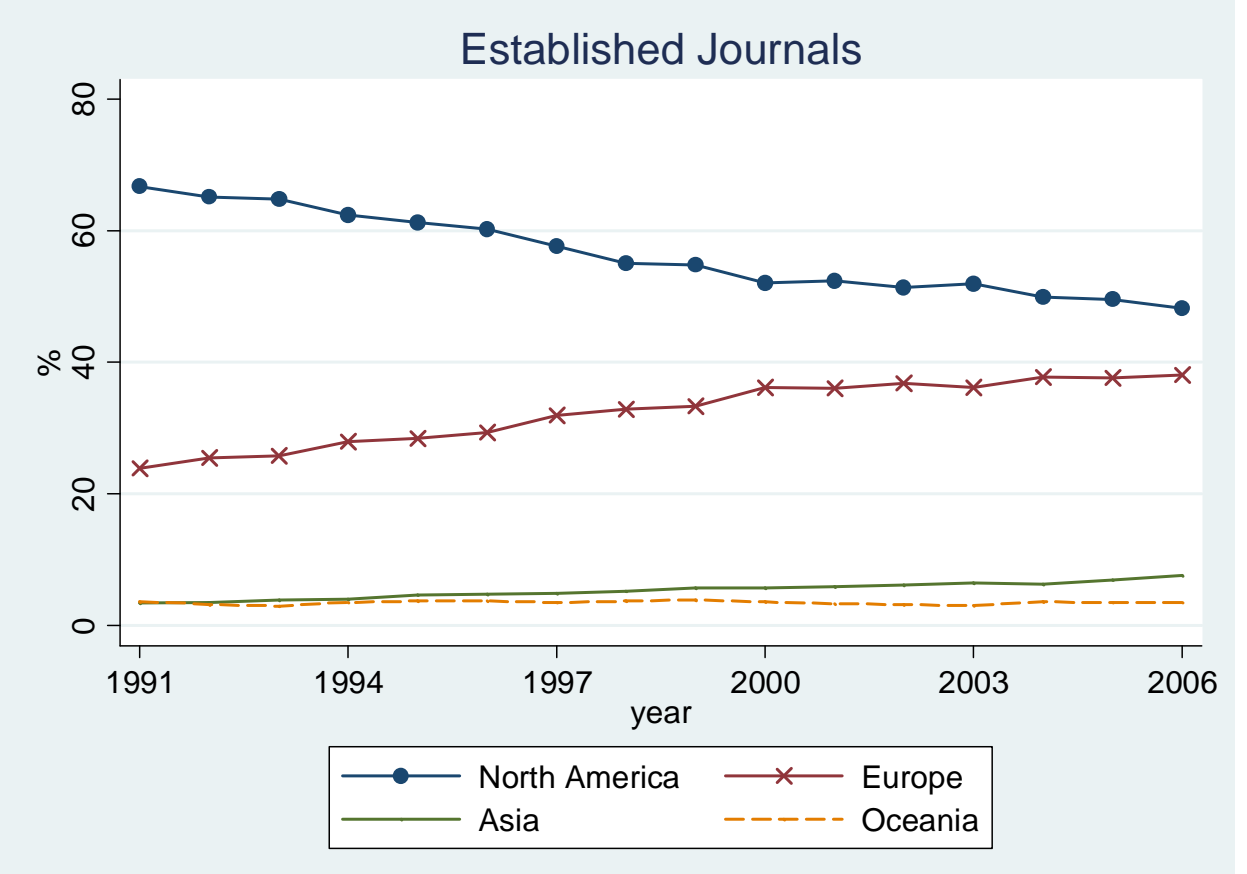

Source: Authors computations based on Econlit and SSCI.

Using the set of established journals, figure 2 still reports a rising contribution of Europe to world scientific production in economics. Nevertheless, the trend is slightly less pronounced than in figure 1, which reported all journals. In established journals, the share of Europe increases from $24 \%$ in 1991 to $38 \%$ in 2006; the Asian share goes from $3 \%$ to $8 \%$; the NorthAmerican share, on the other hand, declines from $67 \%$ to $48 \%$. Overall, we therefore find that Europe is catching up with North-American levels of production, both because it has been delivering more outputs and because it managed to have more of its journals considered in international databases that track academic work in economics around the world.

\section{But in terms of influential research, North-America remains the uncontested leader}

To progress from an analysis of quantity of articles published to an indicator of its influence, we rely on two different criteria. First of all, we restrict the set of journals to a highly selective group of top journals in economics. Secondly, we consider the influence of the article among scholars by relying on the number of citations it received. 
Figure 3 - Evolution of share of articles by continent, top journals

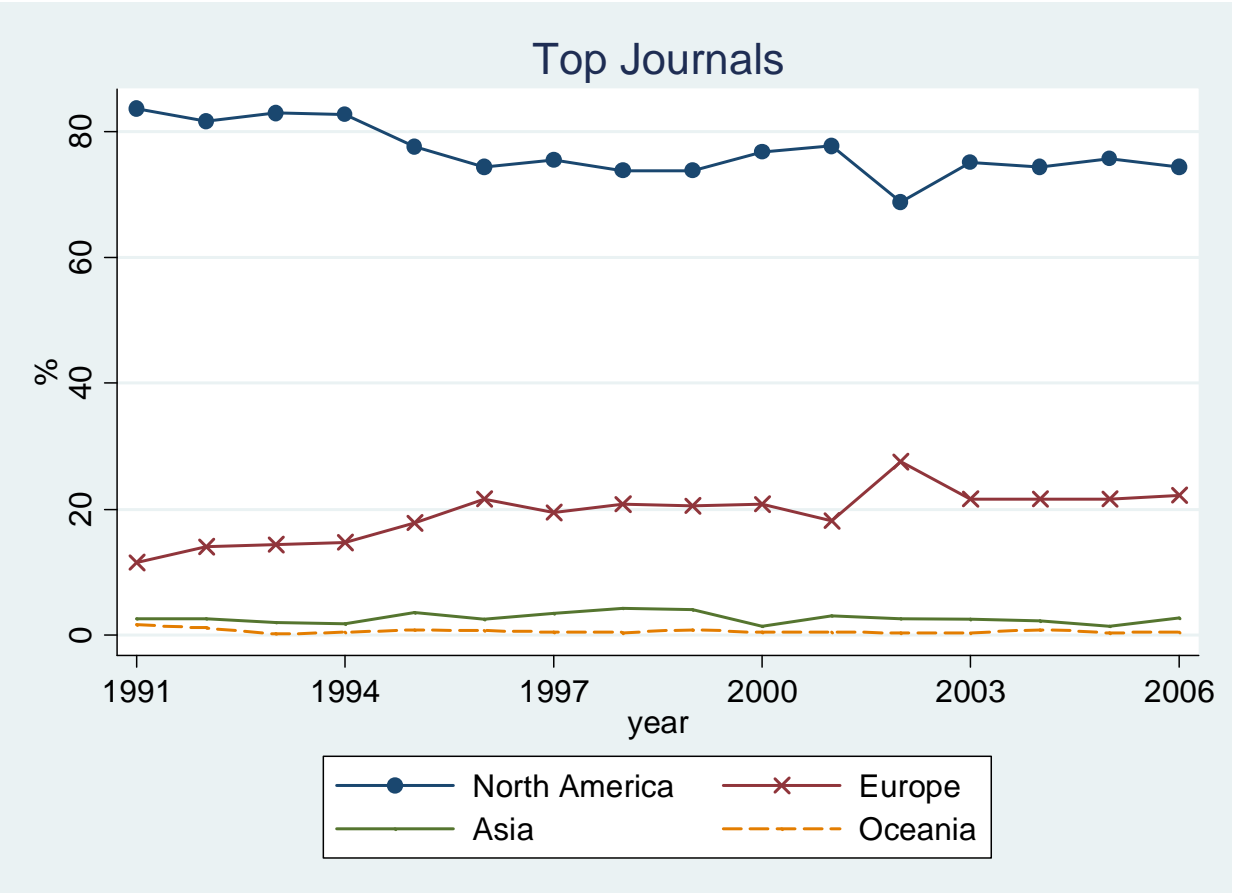

Source: Authors computations based on Econlit and SSCI.

The trend previously detected is different once the analysis is restricted to top journals. We now uncover that the dominance of North-America remains strong. In this group of journals, North-American authors accounted for $85 \%$ of the output in 1991 and $76 \%$ in 2006; the European share went from $14 \%$ to $22 \%$ and the Asian one from $1 \%$ to $2 \%$.

One line of argument close to Europe's heart would claim that the access of European scholars to top journals is restricted, when compared to the easier access those journals would grant to scholars based in North-America. An alternative index of quality of academic work could therefore be considered. The number of citations gathered by an article is widely used as an indicator of how influential the work is (see the arguments in Kim et al, 2006). We thus report in figure 4 the share of citations to European or North American authors, for the different sets of journals. Interestingly, we find that the share of citations to North American authors is consistently above their share of articles, with the opposite holding for European authors. This indicates that the average number of citations received by a North-American author is larger than the average number of citations received by a European author, irrespective of the set of journals considered: all, established or top journals. This is largely driven by the over-representation of North-American authors in top journals, which gather a significantly larger number of citations per article. Another explanation for this gap could be the experience composition of the two sets of authors. It has been shown (eg. Laband, 1986) that work by researchers with a more firmly established reputation is more cited. Most likely, 
the growth in the European contribution reflects the outputs of a new generation, junior researchers that begin to be active in Europe.

Figure 4 - Evolution of share of articles and citations by continent
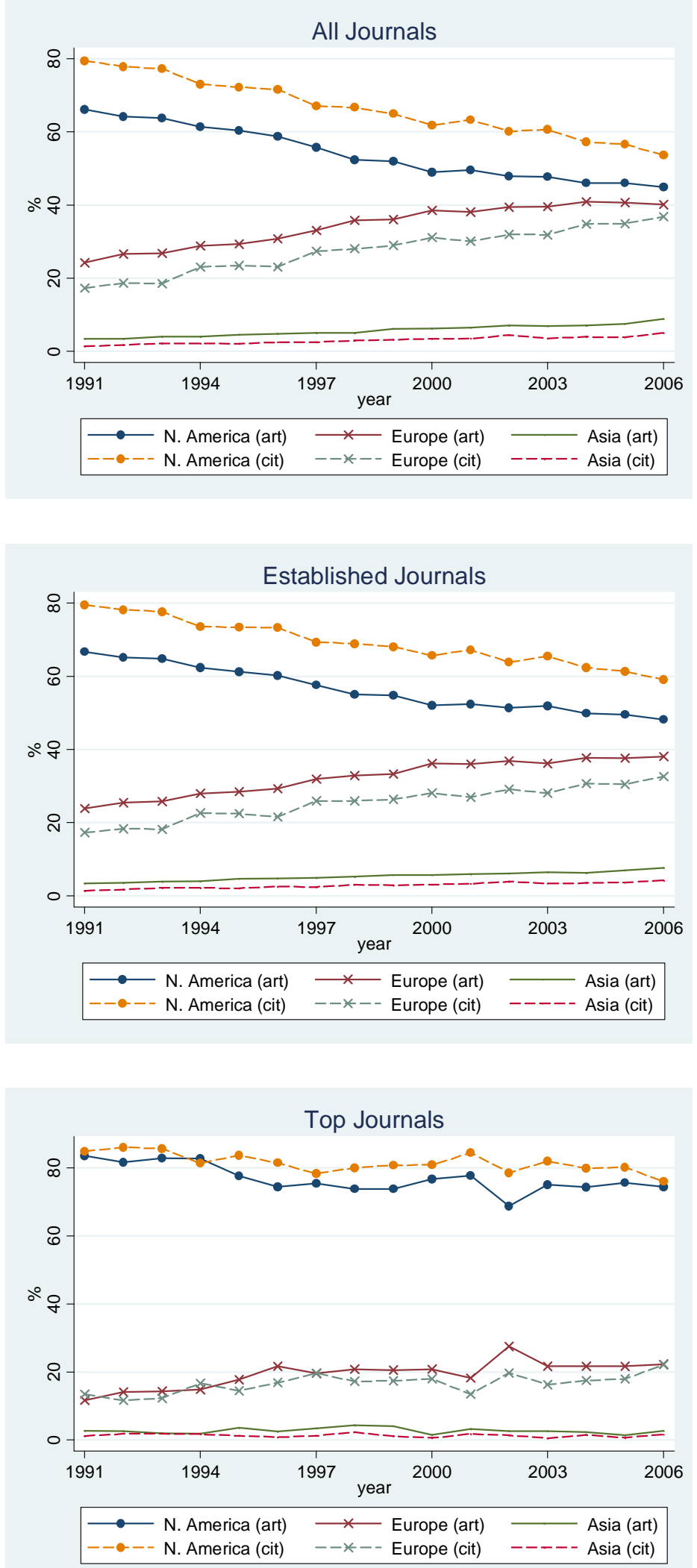

Source: Authors computations based on Econlit and SSCI. 
In terms of trends in the shares of cites and articles, Europe moves up in the sets of all journals and established journals at the expense of the US, while Asia remains largely unchanged. This is also true for top journals, but only to a much smaller extent. As a consequence, the US largely defends its position among the top journals.

At this point, a finer level of analysis is called for. Efforts are underway to turn Europe into a transparent global academic market, but the fact is that currently a very strong segmentation still exists along national borders. Research traditions, as well as current research policies, diverge widely across Europe: while a few countries have long ago adhered to the so-called "Anglo-Saxonic model", others are now at an initial stage of that process; the current policy in some countries has explicit quality aims, while in other countries such awareness is just starting to build up and it has not yet been translated into national policies; there are countries that aim at encouraging a few institutions of excellence, while others aim for a less concentrated basis of research production; a few research sub-areas can make a remarkable difference in some countries, while others rely on a more diversified basis of scientific subfields. We therefore progress to a within-country analysis.

\section{An analysis by country: contrasts among paths}

We focus in this section on the largest countries according to their share of articles in established journals published in 1991-1995' : Austria, Australia, Belgium, Canada, Denmark, France, Germany, Israel, Italy, Japan, The Netherlands, Norway, Spain, Sweden, Switzerland, United Kingdom, and the US.

Figure 5 reports for each country the growth rate in the share of articles in established journals versus the growth rate in the share of articles in top journals. Roughly speaking, we could say that we are evaluating the growth in an indicator that emphasizes quantity against the growth in an indicator that favors quality. To compute the growth rates, we considered 1991-1995 as the initial period and 2002-2006 as the final period and as such we avoid the distortion that could be caused by a potential outlier year for a country.

\footnotetext{
${ }^{6}$ Share of world above $0.5 \%$.
} 
Figure 5 - Growth in the share of articles in established and top journals, by country

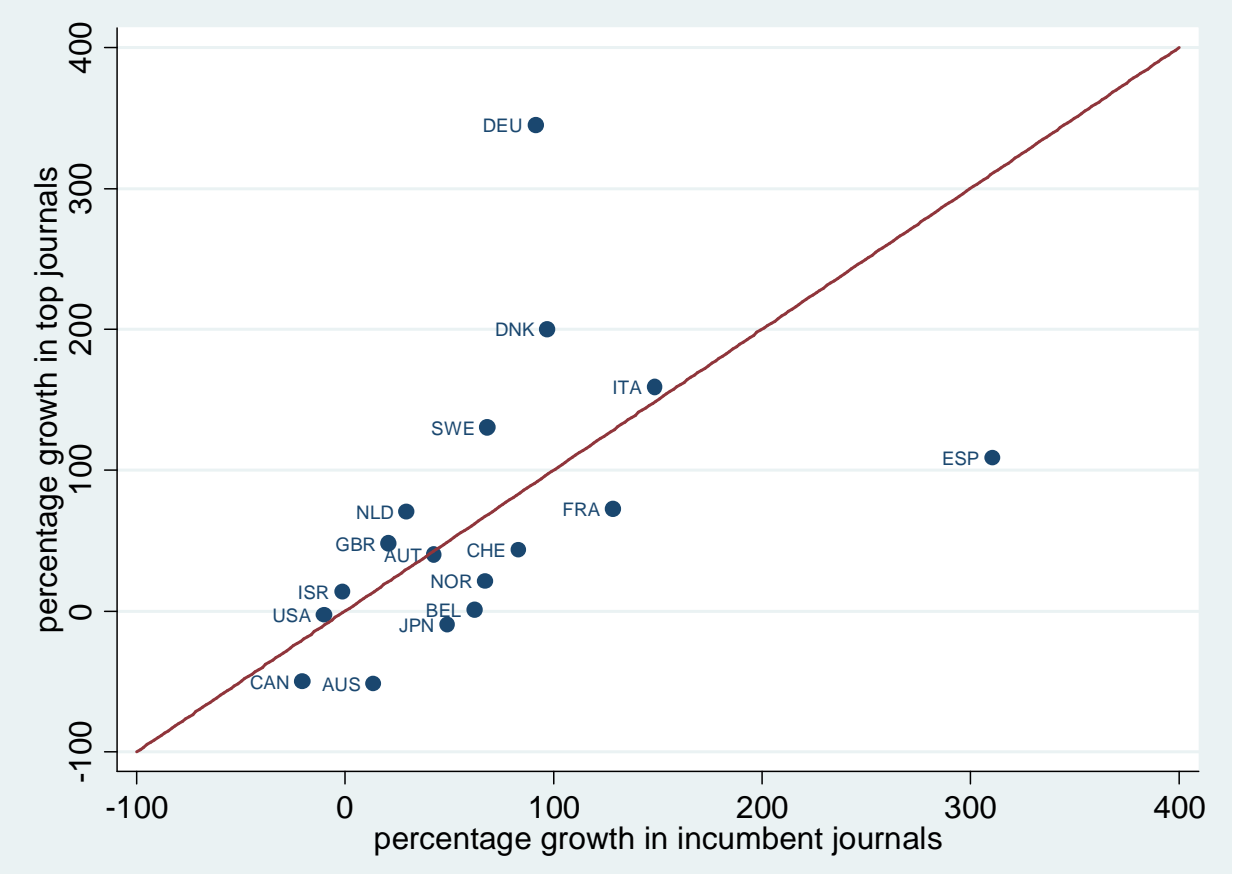

Note: ISO country codes: AUT - Austria; AUS - Australia; BEL - Belgium; CAN - Canada; DNK - Denmark; FRA - France; DEU - Germany; ISR - Israel; ITA - Italy; JPN - Japan; NLD - The Netherlands; NOR Norway; ESP - Spain; SWE - Sweden; CHE - Switzerland; GBR - United Kingdom; USA - USA.

Source: Authors computations based on Econlit and SSCI.

Figure 5 reports a general trend of increasing contribution by European countries to world academic output, both in terms of established and top journals. The growth in the share of articles in top journals is particularly impressive for Germany, but also Denmark, Italy and Sweden showed fast progress, more than doubling their contributions. This increasing penetration of Europe in top world academic production has taken place at the expense of those countries whose contribution declined - mainly Australia and Canada but, to a lower extent, also Japan and the US. In terms of publication in a wider set of established journals, Spain made the most notable progress, with a four-fold increase in its contribution, even though growth in top journals was not as impressive; Italy and France more than doubled their contributions to established journals with Denmark and Germany having a slightly inferior performance. Out of the reported countries, only Canada and the USA registered a decline in the share of articles in established journals.

Of course, growth rates are influenced by departure values, with the very smallest initial contributions more prone to grow faster and, conversely, the biggest countries more likely to grow slower. Table 2 therefore reports the initial and final shares of articles in established and top journals for each country.

The UK reinforced over the period its position as the second largest producer of economic knowledge (table 2). In fact, it consolidated the second position in the share of articles in 
established journals, while in top journals it reached the second position (with $6.4 \%$ of the articles), followed by France (with 3.7\%) and Canada, who lost its initial second position. The Canadian share of $2.8 \%$ now places the country as the fourth contributor to top journals. Israel ranks fifth, having slightly increased its share in top journals (to 2.1\%), despite the slight loss in share in established journals. Spain is now the sixth largest country contributing to top journals $(2.1 \%)$, closely followed by Germany $(1.7 \%)$.

Table 2 - Shares of articles by country (percentage)

\begin{tabular}{l|r|r|r|r}
\hline \multirow{2}{*}{ Country } & \multicolumn{2}{|c|}{ Established journals } & \multicolumn{2}{c}{ Top journals } \\
\cline { 2 - 5 } avg 91-95 & Avg 02-06 & avg 91-95 & avg 02-06 \\
\hline USA & 62.42 & 51.36 & 77.71 & 72.67 \\
UK & 10.63 & 11.78 & 4.43 & 6.37 \\
Canada & 6.57 & 4.79 & 5.96 & 2.86 \\
Australia & 3.26 & 3.39 & 0.93 & 0.43 \\
Germany & 3.08 & 5.40 & 0.46 & 1.96 \\
Netherlands & 2.66 & 3.16 & 0.95 & 1.57 \\
Japan & 1.77 & 2.41 & 1.40 & 1.22 \\
France & 1.69 & 3.55 & 2.19 & 3.65 \\
Israel & 1.43 & 1.30 & 1.94 & 2.13 \\
Italy & 1.13 & 2.57 & 0.70 & 1.76 \\
Sweden & 1.05 & 1.62 & 0.42 & 0.93 \\
Spain & 0.88 & 3.31 & 1.05 & 2.12 \\
Norway & 0.76 & 1.16 & 0.29 & 0.34 \\
Belgium & 0.84 & 1.25 & 0.64 & 0.61 \\
Switzerland & 0.69 & 1.16 & 0.55 & 0.76 \\
Denmark & 0.55 & 1.00 & 0.10 & 0.28 \\
Austria & 0.61 & 0.80 & 0.29 & 0.39 \\
\hline
\end{tabular}

Source: Authors computations based on Econlit and SSCI.

However, country shares in academic output reflect to a large extent country sizes. A better indicator of the emphasis placed by the country on research or the success of its research strategy would be the academic output per million inhabitants. Figure 6 thus depicts for each country the average number of articles in established journals per million inhabitants, in the initial and final periods (1991-1995 and 2002-2006, respectively). 
Figure 6 - Trend in articles per million inhabitants in established journals, by country

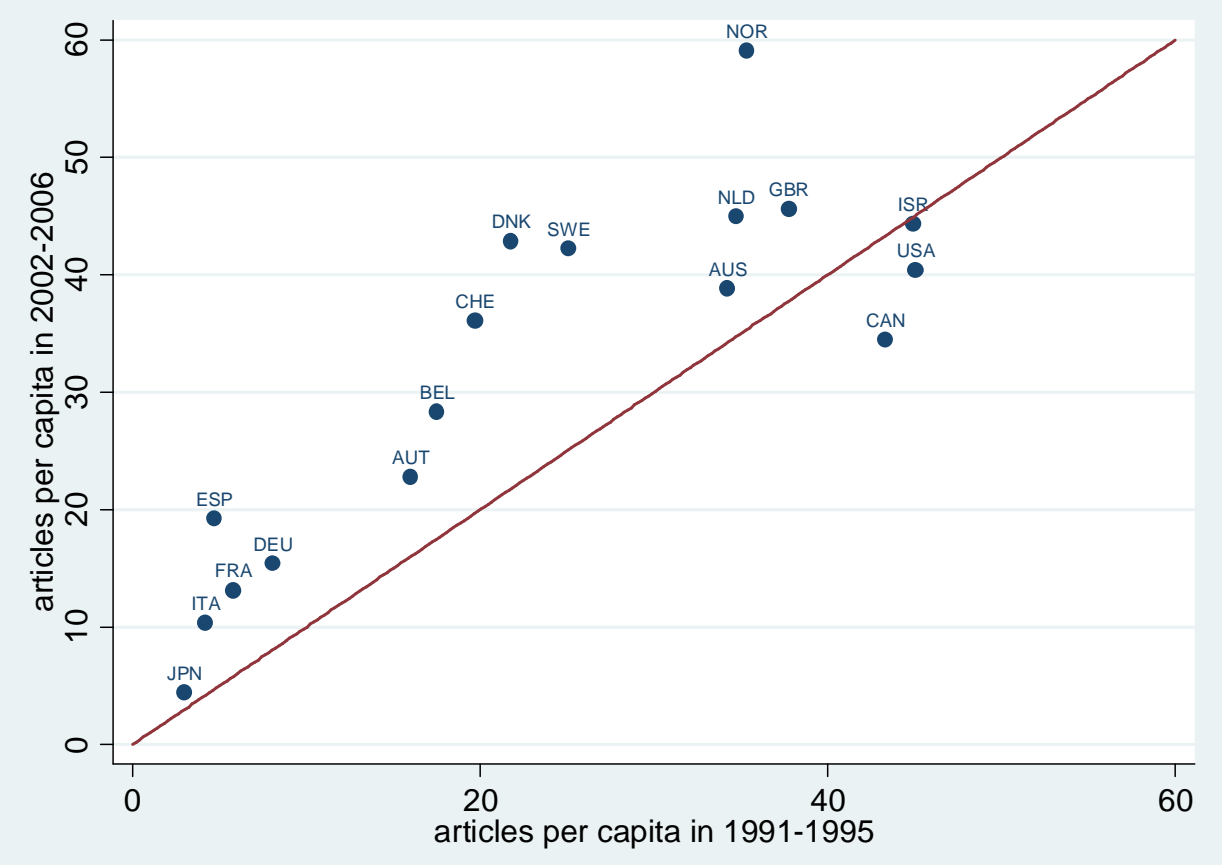

Source: Authors computations based on Econlit and SSCI.

The overall picture is very clear: almost all countries grew in terms of their average academic production per million inhabitants, with the only exceptions being Israel, where the figure remained roughly stable, and Canada and the USA, where it declined. ${ }^{7}$ The USA and Israel had a clear leadership at the beginning of the period, followed by Canada. They lost it to Norway, currently the unambiguous leader in average academic output per capita, with approximately 60 articles in economics journals per million inhabitants. A broad group of countries follows, with more than 40 articles per capita: the UK, Israel, Netherlands, Denmark, Sweden, and the USA, in that order. A cluster with the four large countries in the European Union can be identified: Spain, Germany, France and Italy still rank rather low, with 10 to 20 articles in economics journals per million inhabitants, despite a sharp growth in the past couple of decades. In economics, Japan is clearly lagging behind in academic output per capita.

\footnotetext{
${ }^{7}$ Note that we have kept the denominator unchanged (country population in a reference year, 2006).
} 
Figure 7 - Trend in articles per million inhabitants in top journals, by country

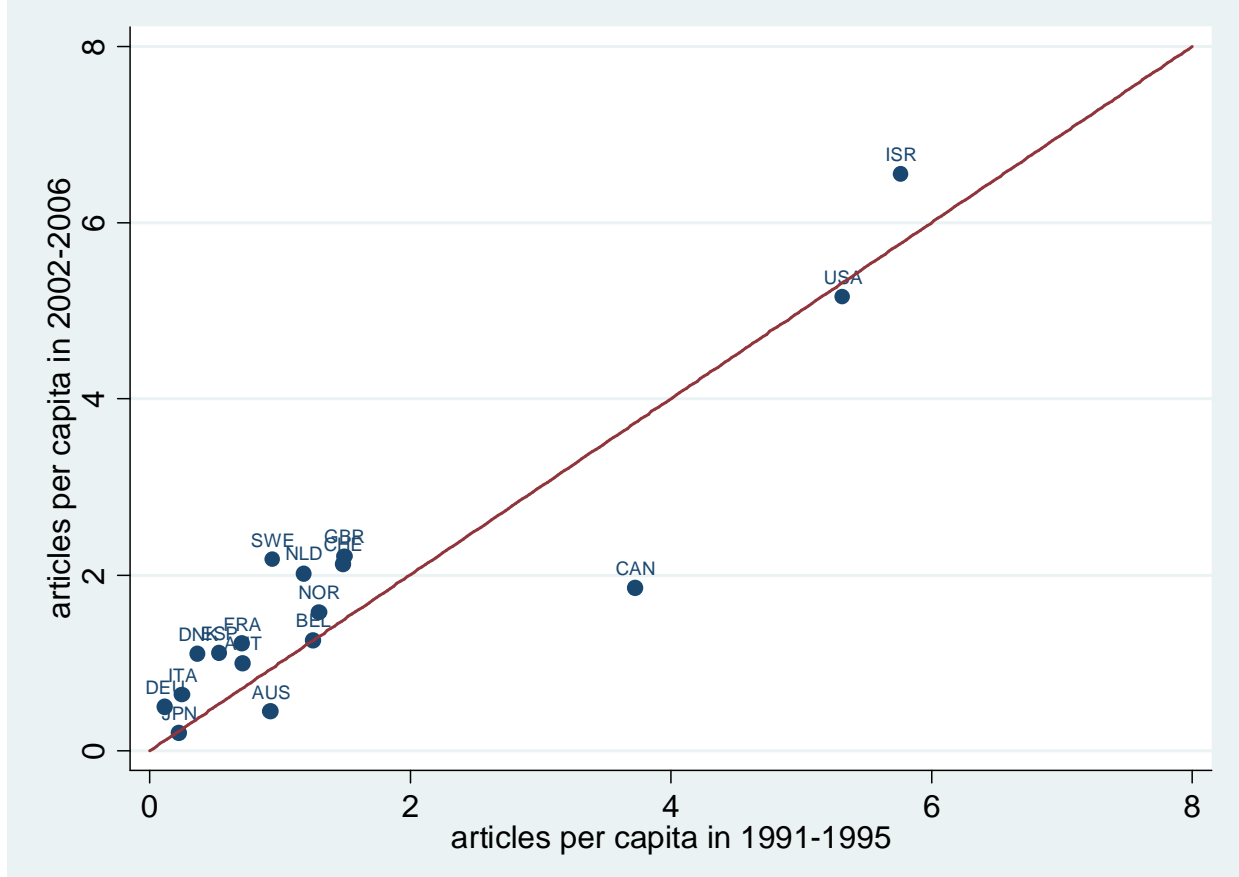

Source: Authors computations based on Econlit and SSCI.

Just like in the analysis by broad continents, a focus on top journals instead of a wider group of journals reveals a slightly different picture. Figure 7 shows the average number of articles in top journals per million inhabitants, in the initial and final periods, for each country. We now find that the top positions occupied by Israel and the USA remain unchallenged. There is however a difference between the trends in these two countries: while the USA kept its average number of articles in top economics journals per million inhabitants at roughly 5 (5.3 and 5.2), Israel increased it from 6 to 7 (more precisely, 5.8 to 6.8). Most other countries are bunched together, with a low average both at the beginning and at the end of the period. Canada is the exception, having lost its initial intermediate position to join the group of countries in the lower tail of the distribution of average number of articles in top journals per capita.

Table 3 reports other indicators of research trends across countries: the degree of academic collaborations (reflected in single- versus joint-authorship of the articles) and the degree of openness of the academic environment, as measured by international collaborations. 
Table 3 - Share of articles according to authorship: single authorship, national collaborations and international collaborations (\%)

\begin{tabular}{|c|c|c|c|c|c|c|c|c|c|c|c|c|}
\hline & \multicolumn{6}{|c|}{ Established journals } & \multicolumn{6}{|c|}{ Top journals } \\
\hline & \multicolumn{3}{|c|}{ avg 1991-1996 } & \multicolumn{3}{|c|}{ avg 2002-2006 } & \multicolumn{3}{|c|}{ avg 1991-1996 } & \multicolumn{3}{|c|}{ avg 2002-2006 } \\
\hline & Single & Nat collab & Intl collab & Single & Nat collab & Intl collab & Single & Nat collab & Intl collab & Single & Nat collab & Intl collab \\
\hline Australia & 49.1 & 26.8 & 24.1 & 33.4 & 35.7 & 30.9 & 45.5 & 27.3 & 27.3 & 18.8 & 0.0 & 81.3 \\
\hline Austria & 59.9 & 15.1 & 25.0 & 27.6 & 28.8 & 43.6 & 25.0 & 25.0 & 50.0 & 45.5 & 0.0 & 54.5 \\
\hline Belgium & 36.7 & 20.4 & 42.9 & 20.6 & 22.7 & 56.7 & 25.0 & 15.0 & 60.0 & 8.0 & 0.0 & 92.0 \\
\hline Canada & 42.2 & 29.1 & 28.8 & 30.8 & 29.1 & 40.1 & 39.7 & 18.6 & 41.7 & 28.1 & 13.5 & 58.4 \\
\hline Denmark & 57.5 & 23.9 & 18.7 & 29.8 & 27.5 & 42.7 & 100.0 & 0.0 & 0.0 & 20.0 & 10.0 & 70.0 \\
\hline France & 38.9 & 22.5 & 38.5 & 23.2 & 31.0 & 45.7 & 35.6 & 18.6 & 45.8 & 17.7 & 23.0 & 59.3 \\
\hline Germany & 58.9 & 21.8 & 19.4 & 36.0 & 28.5 & 35.4 & 38.5 & 7.7 & 53.8 & 20.9 & 11.9 & 67.2 \\
\hline Israel & 34.4 & 19.8 & 45.8 & 22.9 & 27.2 & 49.9 & 22.8 & 15.8 & 61.4 & 24.2 & 13.6 & 62.1 \\
\hline Italy & 46.8 & 21.4 & 31.9 & 29.8 & 26.4 & 43.8 & 35.0 & 10.0 & 55.0 & 11.5 & 12.7 & 76.2 \\
\hline Japan & 60.4 & 18.7 & 21.0 & 51.8 & 27.7 & 20.5 & 54.1 & 5.4 & 40.5 & 48.5 & 12.1 & 39.4 \\
\hline Netherlands & 38.5 & 40.6 & 20.9 & 21.9 & 38.6 & 39.5 & 29.6 & 22.2 & 48.1 & 12.5 & 35.4 & 52.1 \\
\hline Norway & 56.9 & 24.3 & 18.8 & 31.4 & 37.7 & 30.8 & 57.1 & 14.3 & 28.6 & 13.3 & 0.0 & 86.7 \\
\hline Spain & 40.5 & 26.7 & 32.8 & 22.6 & 42.1 & 35.3 & 32.3 & 12.9 & 54.8 & 11.1 & 23.6 & 65.3 \\
\hline Sweden & 47.5 & 32.3 & 20.2 & 35.9 & 34.6 & 29.5 & 45.5 & 9.1 & 45.5 & 29.6 & 14.8 & 55.6 \\
\hline Switzerland & 49.7 & 17.1 & 33.1 & 27.6 & 25.7 & 46.6 & 50.0 & 14.3 & 35.7 & 7.4 & 14.8 & 77.8 \\
\hline UK & 48.5 & 33.7 & 17.9 & 31.0 & 35.4 & 33.6 & 38.3 & 24.3 & 37.4 & 26.2 & 15.9 & 57.9 \\
\hline USA & 47.1 & 43.7 & 9.2 & 33.4 & 50.3 & 16.3 & 45.8 & 44.3 & 9.9 & 29.5 & 52.7 & 17.9 \\
\hline
\end{tabular}

Source: Authors computations based on Econlit and SSCI. 
A few key ideas emerge from table 3 . There is a clear shift towards more collaborative research in economics, particularly pronounced in Austria, Denmark, Norway and Germany. Publishing in top journals was, already at the beginning of the period, more of a joint effort by different authors and the increasing penetration of European authors in top journals was to a large extent accomplished through international co-authorships. Japan, the country with the lowest per-capita output of economic research, stands out as the place where most authors work in isolation.

\section{Conclusion}

We rely on an extremely comprehensive coverage of articles in economics over a long time frame and match different data sources to uncover trends in research productivity across countries. We approach the issue from several angles: research quantity and its quality, either one evaluated using alternative indicators.

Our findings indicate that Europe is catching-up with the US, both because it has been delivering more outputs but also because it has managed to include more of its journals in international databases. However, in terms of influential research, progress has been much slower and the US still maintains a dominant position.

The main continental European countries, Germany, France, Italy and Spain, experienced some of the largest growth rates in economic scientific output. Nevertheless, their per capita output is still substantially below the US. Other European countries, namely Norway, the Netherlands, Denmark, Sweden and the UK, have managed to pass the US in per capita output. However, when the count is restricted to top journals, only Israel shows better performance than the US.

Collaborative research seems to be a key factor in explaining the relative success of some European countries. This is particularly true for publications in top journals which, for most countries, are attained through international collaborations.

\section{References}

Aghion, Philippe, Mathias Dewatripont, Caroline Hoxby, Andreu Mas-Colell, and André Sapir (2010). The Governance and Performance of Universities: Evidence from Europe and the US, Economic Policy. 61: 7-59.

Axarloglou, Kostas and Vasilis Theoharakis (2003). Diversity in Economics: An Analysis of Journal Quality Perceptions, Journal of the European Economic Association. 1: 14021423.

Barrett, Christopher B., Aliakbar Olia, and Dee von Bailey (2000). Subdiscipline-specific Journal Rankings: Whither Applied Economics?, Applied Economics. 32: 239-252. 
Borghans, Lex and Frank Coervers (2009). The Americanization of European Research and Higher Education, IZA discussion paper 4445. Bonn: Institute for the Study of Labor.

Colander, David (2008) The Making of a Global European Economist, Kyklos. 61: 215-236.

Combes, Pierre-Philippe and Laurent Linnemer (2003). Where are the Economists who Publish? Publication Concentration and Rankings in Europe Based on Cumulative Publications, Journal of the European Economic Association. 1: 1250-1308.

Coupé, Tom (2003). Revealed Performances: Worldwide Rankings of Economists and Economics Departments, 1990-2000, Journal of the European Economic Association. 1: 1309-1345.

Drèze, Jacques H. and Fernanda Estevan (2007). Research and Higher Education in Economics: Can We Deliver the Lisbon Objectives?, Journal of the European Economic Association. 5: 271-304.

Fonseca, Gonçalo L. (2010). History of Economic Thought Webpage. http://homepage.newschool.edu/het/essays/journal.htm . Accessed May 10.

Frey, Bruno and Reiner Eichenberger (1993) American and European Economics and Economists, Journal of Economic Perspectives. 7: 185-193.

Frey, Bruno, Reiner Eichenberger and René L. Frey (2009). Editorial Ruminations: Publishing Kyklos, Kyklos. 62: 151-160.

Glaenzel, Wolfgang, Koenraad Debackere, and Martin Meyer (2008). 'Triad' or 'tetrad'? On Global Changes in a Dynamic World, Scientometrics. 74: 71-88.

Grijalva, Therese C. and Clifford Nowell (2008). A Guide to Graduate Study in Economics: Rankings of Economics Departments by fields of Expertise, Southern Economic Journal. 74: 971-996.

Kalaitzidakis, Pantelis, Theofanis P. Mamuneas, and Thanasis Stengos (2003). Rankings of Academic Journals and Institutions in Economics, Journal of the European Economic Association. 1: 1346-66.

Kim, E. Han, Adair Morse and Luigi Zingales (2006). What Has Mattered to Economics Since 1970, Journal of Economic Perspectives. 20: 189-202.

Kirman, Alan and Mogens Dahl (1994). Economic Research in Europe, European Economic Review. 38: 505-522.

Kodrzycki, Yolanda and Pingkang Yu (2006). New Approaches to Ranking Economics Journals, Contributions to Economic Analysis \& Policy. 5: article 24.

Laband, David (1986). Article Popularity, Economic Inquiry. 24: 173-180.

Laband, David N. and Michael J. Piette (1994). The Relative Impacts of Economics Journals: 1970-1990, Journal of Economic Literature. 32: 640-66.

Shelton, Robert and Geoffrey Holdridge (2004). The US-EU Race for Leadership of Science and Technology: Qualitative and Qualitative Indicators, Scientometrics. 60: 353-363.

US Bureau of the Census (2009). International Database, available in http://www.census.gov/ipc/www/idb/, accessed September 29. 